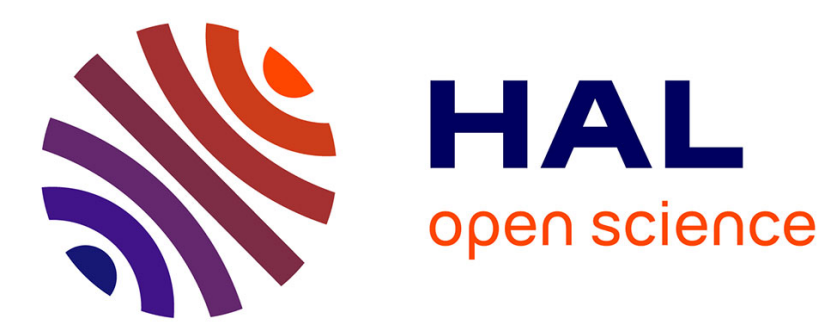

\title{
HF Bistatic Ocean Doppler Spectra: Simulation Versus Experimentation
}

Samuel Grosdidier, Philippe Forget, Yves Barbin, Charles-Antoine Guérin

\section{To cite this version:}

Samuel Grosdidier, Philippe Forget, Yves Barbin, Charles-Antoine Guérin. HF Bistatic Ocean Doppler Spectra: Simulation Versus Experimentation. IEEE Transactions on Geoscience and Remote Sensing, 2013, 10.1109/TGRS.2013.2258352 . hal-00905980

\section{HAL Id: hal-00905980 \\ https://hal.science/hal-00905980}

Submitted on 19 Nov 2013

HAL is a multi-disciplinary open access archive for the deposit and dissemination of scientific research documents, whether they are published or not. The documents may come from teaching and research institutions in France or abroad, or from public or private research centers.
L'archive ouverte pluridisciplinaire HAL, est destinée au dépôt et à la diffusion de documents scientifiques de niveau recherche, publiés ou non, émanant des établissements d'enseignement et de recherche français ou étrangers, des laboratoires publics ou privés. 


\title{
HF Bistatic Ocean Doppler Spectra: Simulation Versus Experimentation
}

\author{
Samuel Grosdidier, Philippe Forget, Yves Barbin, and Charles-Antoine Guérin
}

\begin{abstract}
We simulate the Doppler spectra that can be obtained under experimental conditions from bistatic highfrequency oceanic radar. For this, we combine the bistatic secondorder theory with the characteristics of the full radar system, such as antenna patterns, range attenuation, and postprocessing of the received signal. Because of the sharp variation of the bistatic geometry at short range, we show that it is crucial to take these effects into account for the correct interpretation of the first-order Bragg peaks. The second-order spectrum is more robust to the system characteristics but can under some conditions also suffer from its artifacts, especially in the vicinity of the secondary peaks. A comparison is made with experimental spectra acquired recently with a Wellen radar system on the Mediterranean coast. The Wave Watch III model is used to simulate directional wave height spectra after a preliminary validation with in situ buoy measurements. Experimental and simulated Doppler spectra agree generally well, except in the case where the directional wave spectrum has little energy in the line of sight of the radar.
\end{abstract}

Index Terms-Bistatic high-frequency surface wave radar (HFSWR), Doppler spectrum [power spectral density (PSD)], ocean wave spectum, radar equation.

\section{INTRODUCTION}

$\mathbf{T}$ ODAY, high-frequency surface wave radars (HFSWRs) are routinely used for the remote sensing of the ocean surface. As is well known, the analysis of the Doppler spectrum of the received signal allows the estimation of surface currents [1], [2] as well as wave spectra (e.g., [3]-[7]). HFSWRs have also proven to be potentially useful for target detection and tracking [8], [9]. Most of the HFSWR systems work with colocated transmitters and receivers. However, the monostatic mode raises practical issues such as the coastal space requirement to set up both the transmit and receive antenna arrays and the problem of mutual interference between antennas. These issues can be overcome by resorting to a bistatic radar system, where the emitter and receiver are sited at remote locations. In addition, the bistatic mode increases data product density and area of coverage for similar equipment. In this paper, we

Manuscript received December 20, 2012; revised March 8, 2013; accepted April 5, 2013. This work was supported in part by the Stradivarius Project (FUI and Région PACA).

The authors are with the Department of Modern Optical Instrumentation, Université du Sud Toulon-Var, La Garde cedex 83957, France, and also with the Aix-Marseille Université, Centre national de la recherche scientifique/ Institut national des sciences de l'Univers, Modern Optical Instrumentation, Marseille cedex 13288, France (e-mail: grosdidiersamuel@hotmail.fr; Philippe.Forget@1seet.univ-tln.fr; Yves.barbin@1seet.univ-tln.fr; charlesantoine.guerin@1seet.univ-tln.fr).

Color versions of one or more of the figures in this paper are available online at http://ieeexplore.ieee.org.

Digital Object Identifier 10.1109/TGRS.2013.2258352 report on a bistatic HFSWR that has been recently installed on the coast of the Northwestern Mediterranean Sea. Although this dual system was primarily dedicated to surface current mapping using the MUSIC processing technique [10], it is also possible to investigate with it the bistatic Doppler signature of a radar cell at the sea surface using a beamforming (BF) technique.

Several experimental studies have been made in the bistatic mode, such as estimation of the directional wave spectrum from first-order echoes [11], measurement of surface current velocities [11], [12], vessel detection [13], and wind measurement [14]. Likewise, there have been a number of theoretical works on the subject [2], [15]-[17]. They essentially come to the conclusion that the characteristics of the Doppler spectra under different sea states are similar to the monostatic case with some quantitative differences of geometrical origin.

The main objective of this paper is to assess the dependence of the Doppler simulation on the given experimental configuration. Our main finding is that it is of primary importance to take into account the characteristics of the whole radar system for a relevant simulation of the Doppler ocean bistatic echo in view of the interpretation and inversion of experimental data.

The theory of high-frequency (HF) bistatic Doppler radar cross section (RCS) is reviewed in Section II and adapted to take into account the characteristics of the radar system. The effects of antenna gains, attenuation along the propagation paths, range processing, and time processing are combined into a single radar equation (Section III). A description of the reference datasets is provided in Section IV, and the effect of the corresponding experimental configuration on the simulated data is discussed in Section V. The comparison between theoretical predictions and experimental measurements is presented and discussed in Section VI.

\section{Bistatic THEORY}

Following a small-height small-slope analysis, a bistatic model for the scattering of vertically polarized HF radiation from a well-conducting rough sea surface has been developed in [15], [16], and [18]-[20]. Assuming a pulsed dipole, their approach produces the Doppler spectrum [power spectral density (PSD)], $\sigma(\omega)$, of the bistatic cross section for a finite patch. Here, these results are used assuming an infinite patch (2) and (3), which is equivalent to the incident monochromatic plane wave hypothesis. The geometry and notations of the scattering problem are depicted in Fig. 1. A radar cell on the sea surface can be labeled by its bistatic 


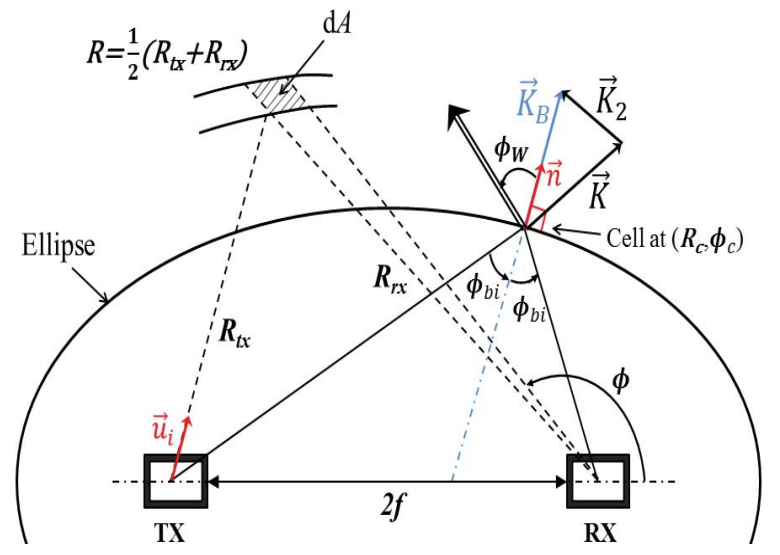

Fig. 1. Bistatic geometry. RX and TX are the receiving and transmitting antenna, respectively. The bistatic range $R$ and the receiving angle $\phi$ are the spatial coordinates of the current point used for (9). The area $\mathrm{d} A$ refers to the integration variable in (9).

range $R$ and its receiving angle $\phi_{c}$. It is also convenient to use the bistatic angle $\phi_{b i}$. The iso-ranges are ellipses with unit normal vector $\boldsymbol{n}$. The Doppler spectrum can be written as the sum of two contributions of leading and corrective order

$$
\sigma=\sigma^{(1)}+\sigma^{(2)} \text {. }
$$

The first term $\sigma^{(1)}$ is due to single-order Bragg scattering. It involves solely the so-called Bragg wave $\boldsymbol{K}_{B}=K_{B} \boldsymbol{n}$ (and counter-Bragg wave, $-\boldsymbol{K}_{B}$ ), where $K_{B}=4 \pi / \lambda_{E M} \cos \phi_{b i}$ is the Bragg wave number and $\lambda_{E M}$ is the electromagnetic wavelength. It writes

$$
\sigma^{(1)}(\omega)=2^{6} \pi^{2} K_{B}^{4} \sum_{\epsilon= \pm 1} \Psi\left(\epsilon \boldsymbol{K}_{B}\right) \delta\left(\omega+\epsilon \omega_{B}\right)
$$

where $\omega_{B}=\sqrt{g K_{B}}$ is the Bragg pulsation, and $\Psi$ is the directional wavenumber spectrum of the elevations at the sea surface. The second term $\sigma^{(2)}$ includes under the same expression the second-order correction for both the electromagnetic and hydrodynamic processes. It can be written in a condensed form, as

$$
\begin{array}{r}
\sigma^{(2)}(\omega)=2^{6} \pi^{2} K_{B}^{4} \sum_{\epsilon_{1,2}= \pm} \int\left|\mathbb{B}\left(\boldsymbol{K}, \epsilon_{1}, \epsilon_{2}\right)\right|^{2} \Psi\left(\epsilon_{1} \boldsymbol{K}\right) \Psi\left(\epsilon_{2} \boldsymbol{K}_{2}\right) \\
\delta\left(\omega+\epsilon_{1} \sqrt{g K}+\epsilon_{2} \sqrt{g K_{2}}\right) \mathrm{d} \boldsymbol{K}
\end{array}
$$

where the wave vectors $\boldsymbol{K}, \boldsymbol{K}_{2}$ are linked by the Bragg condition

$$
\boldsymbol{K}+\boldsymbol{K}_{2}=\boldsymbol{K}_{B} .
$$

The expression of the kernel $\mathbb{B}\left(\boldsymbol{K}, \epsilon_{1}, \epsilon_{2}\right)$ is recalled in Appendix VII. It can be verified that the expressions (2) and (3) reduce to the monostatic formulation of [2] when $\phi_{b i}=0$.

The above expressions for the first- and second-order PSD involve sharp resonance frequencies in the Dirac functions. This implies two singular peaks at plus or minus the Bragg pulsation (2) and reduces the twofold integral (3) to a single integral. In practice, the Dirac functions have to be replaced by peaks of finite width and amplitude because of several combined physical (e.g., variation of orbital velocity) and postprocessing effects (e.g., finite integration time at the receiver).

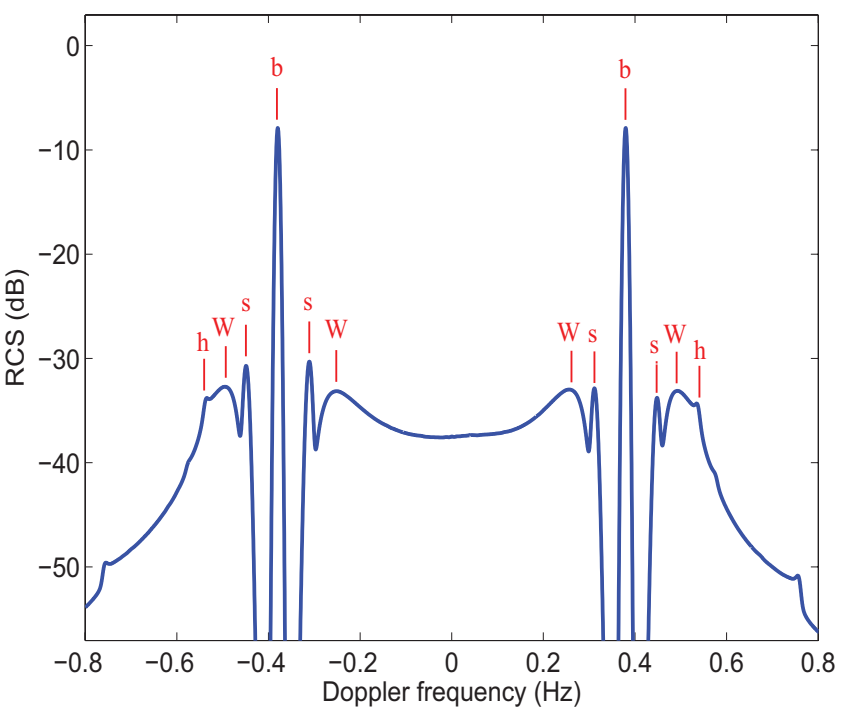

Fig. 2. Bistatic cross-wave Doppler spectrum at radar frequency $16 \mathrm{MHz}$ and bistatic angle $\phi_{b i}=30^{\circ}$. (b) Bragg peaks, (h) second-order hydrodynamic peaks, (w) local maxima generated by wind waves, and (s) swell peaks.

This means that the actual PSD is a smoothed version of the theoretical one

$$
\tilde{\sigma}(\omega)=\int \sigma\left(\omega^{\prime}\right) \mathrm{F}\left(\omega-\omega^{\prime}\right) \mathrm{d} \omega^{\prime}
$$

for some positive filter F. Correspondingly, the first-andsecond-order cross sections for finite integration time are given by

$$
\tilde{\sigma}^{(1)}(\omega)=4 \pi^{2} K_{B}^{4} \sum_{\epsilon= \pm 1} \Psi\left(\epsilon \boldsymbol{K}_{B}\right) \mathrm{F}\left(\omega-\epsilon \omega_{b}\right)
$$

and

$$
\begin{aligned}
\tilde{\sigma}^{(2)}(\omega)=4 \pi^{2} K_{B}^{4} \sum_{\epsilon_{1,2}= \pm 1} \int\left|\mathbb{B}\left(\boldsymbol{K}, \epsilon_{1}, \epsilon_{2}\right)\right|^{2} \\
\mathrm{~F}\left(\omega+\epsilon_{1} \sqrt{g K}+\epsilon_{2} \sqrt{g K_{2}}\right) \Psi\left(\epsilon_{1} \boldsymbol{K}\right) \Psi\left(\epsilon_{2} \boldsymbol{K}_{2}\right) \mathrm{d} \boldsymbol{K} .
\end{aligned}
$$

A typical bistatic Doppler spectrum is illustrated in Fig. 2 for a mixed sea state (wind waves and swell) at the radar frequency $16 \mathrm{MHz}$ and bistatic angle $\phi_{c}=30^{\circ}$. The omnidirectional wind wave spectrum is a standard Pierson-Moskovitz spectrum [21] with a wind speed of $11 \mathrm{~m} / \mathrm{s}$ at $19.5 \mathrm{~m}$ above the sea. This spectrum is combined with a classical spreading function ( $s=4$ and $\epsilon=10^{-2}$, see the Appendix) in the cross-wind configuration $\left(\phi_{W}=-90^{\circ}\right)$. A Gaussian swell spectrum has been superimposed on the wind wave spectrum in a cross-swell configuration (the dominant direction of wave propagation is $\phi=-90^{\circ}$ ). The dominant wavelength of the swell is $230 \mathrm{~m}$. The dominant swell amplitude is $1 \mathrm{~m}$. The integration time has been set to $T_{i}=4 \mathrm{~min}$. The salient features of the Doppler spectrum are similar to those observed in the monostatic case. The first-order Bragg peaks (b) $\left(\omega= \pm \omega_{B}\right)$ provide the leading contribution. There are secondary peaks such as the so-called second-order hydrodynamic peaks (h) at

$$
\omega_{h y d}= \pm \sqrt{2} \omega_{b}
$$


as well as the swell peaks (s). In addition to these peaks, there is a continuum arising from second-order contributions. The spectral peak of the omnidirectional wave spectrum appears as four local maxima (w) on both sides of each Bragg peak.

\section{DOPPLER SPECTRUM UNDER EXPERIMENTAL CONDITIONS}

The aforementioned analytical theory for first- and secondorder bistatic radar return is devised in the ideal mathematical case of an incident monochromatic plane wave impinging on an infinite statistically homogeneous surface. To be more consistent with experimental measurements, some authors have considered realistic emitted wave forms such as a pulsed wave [15] or a frequency-modulated continuous wave (FMCW) [17] under the assumption of narrow beam and remote source and receiver. We employ here a different model, which allows us to simulate the average Doppler spectra for coarse beam resolution in the bistatic configuration at a short range. For this, we need to take the following effects into account.

1) For a given targeted cell, the entire illuminated area contributes to the received power. The contribution of a patch is given by the spatial resolution of the radar system.

2) The bistatic angle varies over the illuminated area.

3) In an FMCW radar, the range corresponds to a frequency shift in the received chirps. In order to reduce the effect of range sidelobes (Gibbs oscillations), each received chirp is multiplied by a weighting window prior to the Fourier transform [22]. It results in a smeared range resolution, which can be described by a spatial window $W$.

4) The time series corresponding to every discriminated range is coherently recorded and processed over a duration called the integration time $\left(T_{i}\right)$. The PSD is obtained by averaging the periodogram over several integration times. Again, to avoid Gibbs oscillations, the signal is multiplied by a weighting window over the integration time. This results in spectral smearing [see (5) for the smoothed PSD].

From these considerations and the radar equation, we may write the experimental PSD at the output of the radar system as

$$
\sigma_{\exp }(\omega)=\int_{\text {sea }} \mathcal{G} \tilde{\sigma}(\omega) \mathrm{d} A
$$

We will refer to $\mathcal{G}$ as the "cell weighting function." It is given by

$$
\mathcal{G}=P_{e} \frac{\lambda_{E M}^{2}}{(4 \pi)^{3}} \frac{F_{t} G_{t} F_{r} G_{r}}{R_{t x}^{2} R_{r x}^{2}} W
$$

where $P e$ is the transmitted power. $R_{t x}$ and $R_{r x}$ are the distance from the patch to the transmitter and the receiver, respectively. The integration is in principle performed over an infinite surface, but the range processing window $W$ and the antenna gains $G_{t}, G_{r}$ limit the effective domain of integration. The terms $F_{t}, F_{r}$ are the surface wave attenuation factor over the transmit and receive paths, respectively. They account for losses due to the finite conductivity of sea water, earth's curvature, sea surface roughness [23], and island shadowing

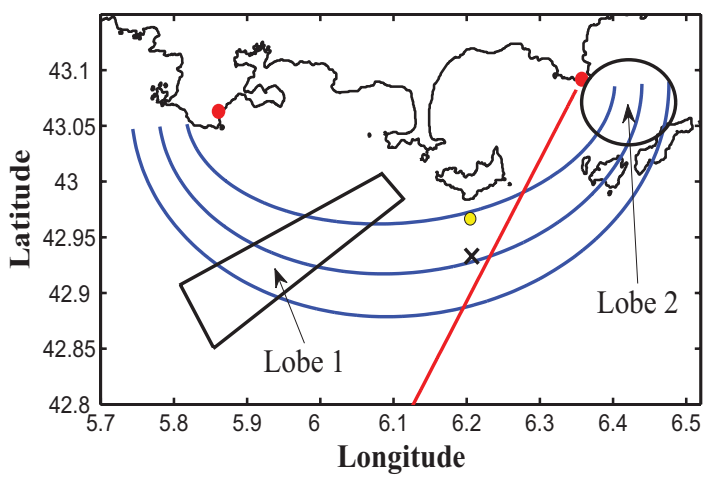

Fig. 3. Map of the experiment. The emitter is located at Cap Sicié (red point on the left) and the receiver at Cap Bénat (red point on the right). The CANDHIS buoy is close to the Porquerolles Island (yellow point) and to the grid point of WW3 model (cross). The iso-range ellipses are shown for $R=24 \mathrm{~km}, R=27 \mathrm{~km}$, and $R=30 \mathrm{~km}$. The red line indicates the radar aiming direction $\phi=-120^{\circ}$.

(see [24] for an overview on ground wave propagation theory). All the quantities involved in the integration implicitly depend on the bistatic range $(R)$ and angle $(\phi)$ as well as on the central coordinates $\left(R_{c}, \phi_{c}\right)$ of the targeted cell. The surface element of integration $d A$ with respect to the coordinates $(R, \phi)$ is given in the Appendix.

\section{REFERENCE DATASETS}

We now describe the reference datasets that have been used to assess the capabilities of the aforementioned simulator. The experiment was conducted with two Wellen Radar (WERA) systems [22], [25] manufactured by Helzel Messtechnik $\mathrm{GmbH}$, and the present data were acquired during a period of 3 weeks in December 2011. These radars are routinely operated at the Mediterranean Institute of Oceanography [26] for real-time sea surface current monitoring. They work at a carrier frequency $f_{c}=16.150 \mathrm{MHz}$ with a sweep bandwidth $B=50 \mathrm{kHz}$. Both receive and transmit systems use very stable master oscillators synchronized with GPS signals. Synchronization methods have already been successfully implemented for years in metrology and communication systems [27], and later in radio oceanography applications [28], [29].

The TX station is installed on the coastal ridge Cap Sicié at $190 \mathrm{~m}$ altitude and about $450 \mathrm{~m}$ away from the shore $\left(43.06^{\circ} \mathrm{N}\right.$ and $5.86^{\circ} \mathrm{E}$, see Fig. 3). The radiated power is about $20 \mathrm{~W}$. Two vertical resonant electric monopoles (and their ground planes) are fed in an end-fire configuration with the main wide lobe directed towards the sea. The RX array has been installed $40.4 \mathrm{~km}$ away from the TX station at Cap Bénat. It has been mounted over the hill slope amid the typical Mediterranean forest at an altitude $165 \mathrm{~m}$ and about $400 \mathrm{~m}$ away from the shore $\left(43.092^{\circ} \mathrm{N}\right.$ and $6.357^{\circ} \mathrm{E}$, see Fig. 3). Eight vertical electric monopoles and their ground planes form an almost perfect periodic linear array $\left(0.45 \lambda_{\mathrm{EM}}\right.$ spacing $)$. To ensure phase stability and to avoid variable influence of the surroundings, the antennas have been slightly resistively loaded. The global directional phase response of the array has been measured using a CW radio beacon aboard a ship 
covering an area of about $270^{\circ}$ around the station. Even though the extraction of the radial component of sea surface current is performed in real time at the RX station, the individual antenna signals are recorded and can be reprocessed on demand. A total of 183 Doppler spectra sampled every $3 \mathrm{~h}$ were selected. This sampling is the same as for the wave model described below (WW3 model). Each sample is computed by averaging 15 consecutive Doppler spectra. The integration time of each spectrum is 265 s corresponding to 1024 chirps with a pulse repetition period of $0.26 \mathrm{~s}$.

The National Center for Archiving Swell (CANDHIS) [30] provides measurement of sea elevations from a wave rider. We used data from a buoy located in deep water behind Porquerolles Island relative to the receiver $\left(42.9667^{\circ} \mathrm{N}\right.$ and $6.2048^{\circ} \mathrm{E}$, Fig. 3). This location is in the short range of the radar system. The French institute PREViMer [31] provided directional wave spectra $3.5 \mathrm{~km}$ southeast of the wave rider buoy (Fig. 3). These spectra have been simulated with the WaveWatch III model (WW3) [32]-[34]. The angular resolution of supplied wave spectra is $15^{\circ}$ and the frequencies extend from 0.037 to $0.72 \mathrm{~Hz}$. Wind forcing is provided by ECMF analysis at $0.5^{\circ}$ resolution. Since the wind parameters considered here are from the WW3 dataset, they have been verified for reliability by comparison with wind measurements at Porquerolles Island.

\section{EFFECT OF THE RADAR SySTEM}

The received periodic time series is usually multiplied by a Blackmann-Harris function. This process can be modeled by the convolution of the Doppler spectrum with the PSD of the function. To simplify the calculation in (5), the frequency filter $F$ is assumed to be Gaussian instead of the PSD of the Blackmann-Harris function

$$
\mathrm{F}(\omega)=\frac{1}{\sqrt{2 \pi} s} \exp \left(-\frac{\omega^{2}}{2 s^{2}}\right) .
$$

The standard deviation $s$ is chosen such that the $3-\mathrm{dB}$ bandwidth $\left(s_{3 d B}\right)$ coincides with the 3-dB bandwidth of the Blackmann-Harris PSD $\left(\simeq 4 \pi / T_{i}\right)$, i.e., $s=1.7 \pi / T_{i}$.

The calculation of the integral in (9) is performed through a discretization of space in radar cells of widths $\Delta R$ and $\Delta \phi$. These parameters should be chosen small enough so as to assume a constant Bragg vector [consequently a constant $\tilde{\sigma}(\omega)$ ] inside each cell. We found that the choice $\Delta R=1000 \mathrm{~m}$ and $\Delta \phi=1^{\circ}$ ensures this condition.

The antenna gains $G_{t}, G_{r}$ in the direction of integration have been estimated using in situ ship measurements. For WERA, the range resolution window $W$ can be approximated by the PSD of the Blackman-Harris function [22].

Equation (9) has been computed for short ranges $(R \leq 40 \mathrm{~km})$ at the radar frequency $16 \mathrm{MHz}$. In this configuration, the total propagation attenuation $F_{t} F_{r}$ along the free sea surface path is almost constant over the sea area where the weighting function is significant. The main variations of the attenuation functions are due to the island shadowing effect of the islands. These islands consist of rough topography with cliffs. Recently, advanced methods [35]-[37] have been developed to simulate mixed path

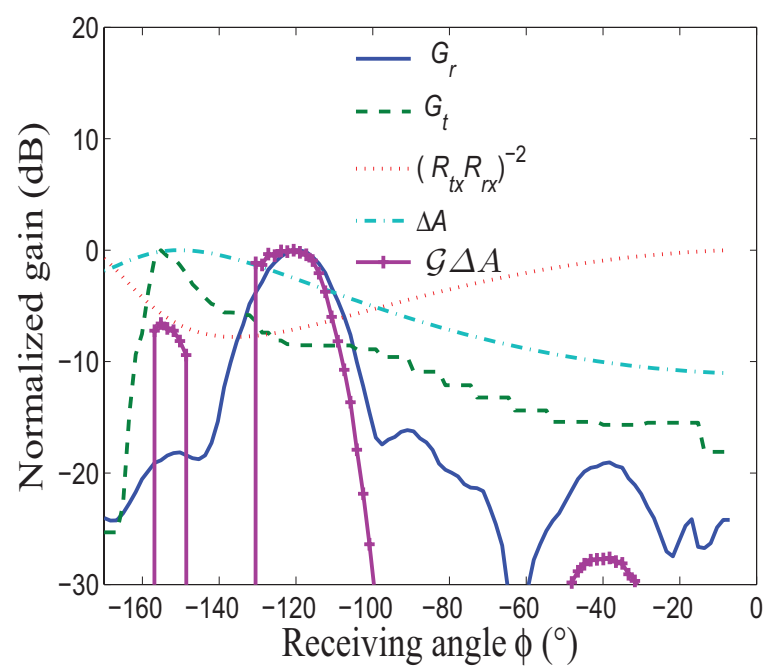

Fig. 4. Azimuthal variation of the different factors in the cell weighting function for a target cell at $R_{c}=27 \mathrm{Km}$ and $\phi_{c}=120^{\circ}$. All quantities have been normalized by their maximum.

propagation losses. Simulation in [36] exhibits a strong loss behind a hilly island with sharp discontinuity. Therefore, as this mask effect dominates all other factors useful in our study, we decided to simply ignore the paths crossing the islands. Accordingly, we simply set the propagation factor to 0 for paths crossing the islands (and 1 otherwise).

The CANDHIS buoy is situated at bistatic coordinates $R=24.3 \mathrm{~km}$ and $\phi=-132^{\circ}$. However, it is difficult to simulate the radar return at such small ranges for two reasons. First, the Bragg frequency varies sharply with the aiming direction. Second, some points of the iso-bistatic range ellipse can be close to the transmitter or receiver. The corresponding large values of $\left(R_{t x} R_{r x}\right)^{-2}$ can pollute the signal when combined with a secondary antenna lobe. An additional difficulty is that the buoy is hidden from the transmitter by the Porquerolles Island. Therefore we chose to focus on another target cell $\left(R_{c}=27 \mathrm{~km}\right.$ and $\left.\phi_{c}=-120^{\circ}\right)$, assuming that the sea state has not changed from one location to another.

The different terms involved in the radar equation (9) are plotted in Fig. 4 for this target cell. The terms are given as a function of azimuth at the range of the target cell. Superimposed is the angular variation of the cell weighting function (10) times the surface element, $\mathcal{G} \Delta A$. As seen, the azimuthal resolution of the radar system is very poor. This means that the variations of the local Bragg vector within the cell cannot be ignored and (6) and (7) based on a plane wave formalism no longer hold. Furthermore, strong sidelobes are visible around the direction $\phi=-153^{\circ}$. These weaknesses can limit the capability to estimate waves and currents from experimental Doppler spectra, as most of the inversion methods rely on these equations [6].

Fig. 6 compares simulated Doppler spectra with and without a cell weighting function at the same target cell $\left(R_{c}=\right.$ $27 \mathrm{~km}$ and $\phi_{c}=120^{\circ}$ ). The strongest side lobe at $-150^{\circ}$ was eliminated using a basic rejector process with a $\mathrm{BF}$ technique. A Pierson-Moskovitz wave spectrum has been used $\left(H_{s}=1.7 \mathrm{~m}\right)$ with no surface current and a relative wind 


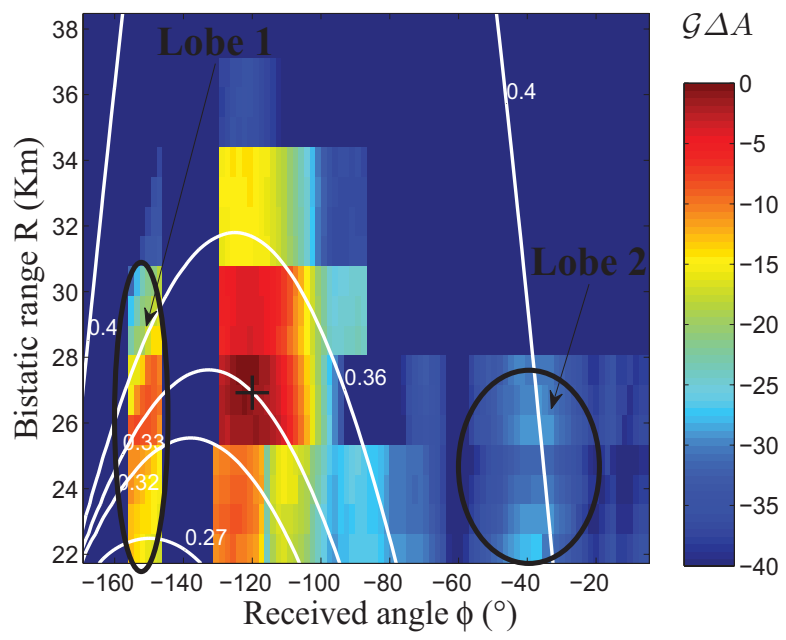

Fig. 5. Azimuthal and range variation of the amplitude $g \Delta A$ in the radar equation for a target cell at $R_{C}=27 \mathrm{~km}$ and $\phi_{c}=120^{\circ}$. The cross indicates the target cell position $\left(R_{c}=27 \mathrm{~km}\right.$ and $\left.\phi_{c}=120^{\circ}\right)$. White curves correspond to different Bragg frequencies (in $\mathrm{Hz}$ ). The side lobes observed around $-150^{\circ}$ can be minimized using a basic rejector process.

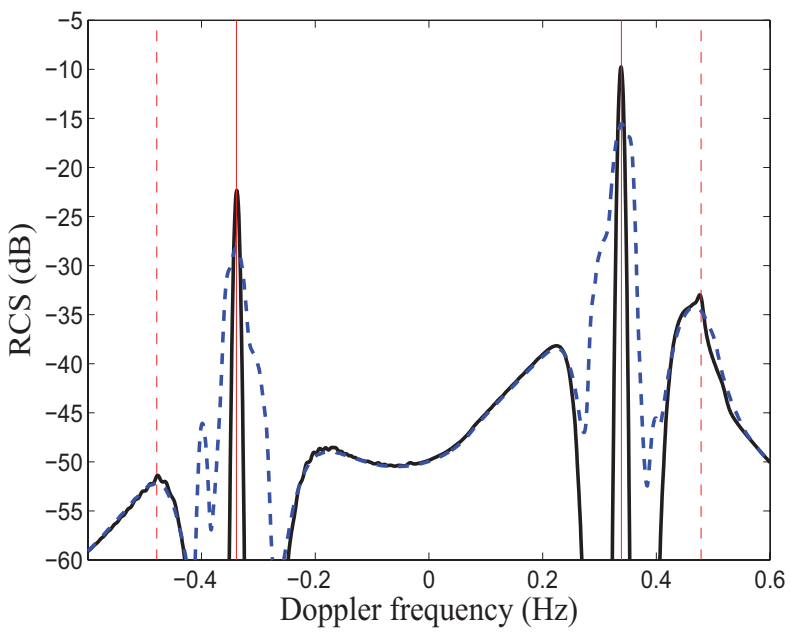

Fig. 6. Doppler spectra with ( $\sigma_{\text {exp }}$, dashed curve) and without $(\tilde{\sigma}$, solid curve) cell weighting function. Solid lines indicate the Bragg peaks position. Dashed lines indicate the second-order hydrodynamic peaks.

direction $\phi_{w}=180^{\circ}$. The integration time is $4.43 \mathrm{~min}$. The parameters of the spreading function are $s=4$ and $\epsilon=10^{-2}$. Doppler spectra have been normalized by the energy of the second-order spectrum.

A salient feature of real spectra is the broadening of the Bragg peaks with respect to the theoretical prediction. This can be explained by the diagram of Fig. 5, which shows that the Bragg frequency varies in the vicinity of the processed target cell. Therefore, the broadening of the peaks reflects the actual width of the main lobe of the radar system. It is an important issue raised by the bistatic configuration. The variation of the Bragg frequency inside the main azimuthal lobe can be much larger than the frequency shift due to the presence of usual surface currents (several tens of centimeters per second) and then hinders the estimation of the surface current. It is commonly observed in the monostatic case that the width of the Bragg peaks can exceed the width predicted by the finite integration time. This is usually attributed to various phenomena such as wave orbital velocities [38] and finite area and time illumination [39], [40]. These mechanisms still apply to the bistatic configuration.

Another feature is the existence of peak at $-0.4 \mathrm{~Hz}$. This peak originates from scattering effect due to the secondary lobe located around $\phi=-50^{\circ}$ and $R=26 \mathrm{~km}$, where $f_{B}$ is close to $-0.4 \mathrm{~Hz}$. Here too, this interpretation is specific to the bistatic configuration for which the Bragg frequency cannot be considered constant as in the case of monostatic radar systems. The amplitude of the peak is smaller than the Bragg peak by only $-20 \mathrm{~dB}$. This value is much greater than the gain ratio between secondary and main lobes $(-30 \mathrm{~dB})$. This difference $(10 \mathrm{~dB})$ is due to the change of geometry yielding stronger Bragg waves in the secondary lobe than in the main lobe. For particular sea state condition, the ratio between this peak and Bragg peak can be much larger. This analysis has been conducted in absence of surface currents. Currents can significantly modify the position of secondary peaks relative to the Bragg peaks.

Following our observations, the introduction of antenna gains in the calculation of the PSD modifies the theoretical first-order peaks both in position and amplitude. This can limit their use at short range (due to the strong variability of the Bragg frequency) for the estimation of surface currents based on the shift of the Bragg peaks and the estimation of wind wave direction based on the ratio of positive and negative Bragg peaks [41], [42]. In addition, the presence of secondary lobes can also mask the sharp swell peaks at short range. The cell weighting function has only a small effect on the secondorder Doppler spectrum (see Fig. 6) except in the vicinity of the hydrodynamic and electromagnetic peaks (Section II) which are smoothed. Hence, the second-order spectrum is more robust to the effects of antenna gains and could be used for oceanographic purposes such as wave spectrum inversion.

\section{EXPERIMENTAL COMPARISON}

\section{A. Bragg Ratio}

We begin with the analysis of the Doppler signal through the Bragg line ratio (BLR), which is the ratio of amplitude of the first-order peaks in the Doppler spectrum. According to (2), the Bragg peaks are generated by short waves $\left(f_{B}=0.34 \mathrm{~Hz}\right.$ at the selected radar cell) and the BLR reflects the directional properties of these waves. Since short waves are likely to be aligned with the wind, except in calm conditions, BLR can be considered as a proxy of the wind direction relative to the radar aiming direction as defined in Fig. 1 [41], [43]-[45]. Fig. 7 shows the BLR measurements versus the relative wind direction $\phi_{w}$ (taken in absolute value) for wind speed larger than $6 \mathrm{~m} / \mathrm{s}$. The variation of the BLR with $\phi_{w}$ is consistent with many previous $\mathrm{HF}$ and VHF observations in the monostatic mode [42], [46]. The values of the BLR are found to be close to $-15 \mathrm{~dB}$ in downwind and $-5 \mathrm{~dB}$ in cross-wind condition.

The experimental BLR have been compared with simulated values using WW3 spectra according to the bistatic theory 


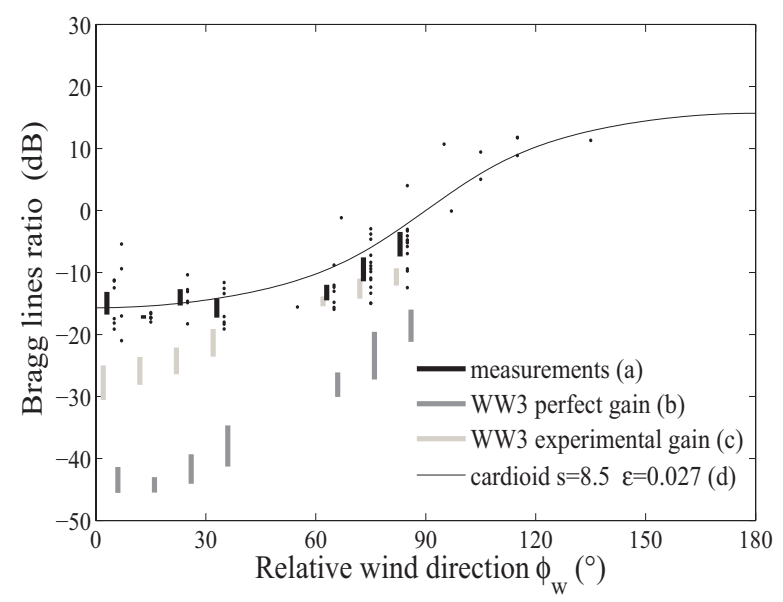

Fig. 7. Bragg line ratio versus relative wind direction $\phi_{w}$ as obtained with (a) our radar measurements, (b) theoretical bistatic model using a WW3 spectrum, (c) simulated model in experimental conditions using a WW3 spectrum, and (d) simple cardioïd model.

with $\left(\sigma_{\exp }\right)$ and without $(\tilde{\sigma})$ the cell weighting function. In the former case, large differences between experimental and theoretical BLR values are observed, e.g., of $30 \mathrm{~dB}$ in up/down wind condition. Such high differences can be significantly reduced (to $13 \mathrm{~dB}$ ) but not suppressed when the cell weighting function is considered. Possible explanations for this discrepancy are spatial inhomogeneity of the wave spectrum over the radar coverage and the validity of WW3 wave spectrum, especially for short waves propagating in the upwind direction. A better agreement is found for relative wind directions in the angular sector $0-45^{\circ}$.

Note that the dependence of the BLR on the relative wind direction can been modeled using a classical spreading function (see Appendix VII). A cardioid model with $s=8.5$ and $\epsilon=0.027$ provides a satisfactory fit with the data.

\section{B. Doppler Spectrum}

We now compare experimental Doppler spectra and simulations using WW3 model. The 183 spectra defined in Section IV were analyzed. We have observed that omnidirectional WW3 spectra can noticeably differ from the CANDHIS buoy spectra. The difference between in situ and modeled wave estimation is mainly due to the grid of resolution of WW3, which is probably too large a coastal area to accurately match the measurements at a specified location. We therefore decided to select the dates at which WW3 and experimental spectra agree best. This agreement was evaluated according to four distinct criteria: 1) wind speed at Porquerolles station larger than $6 \mathrm{~m} / \mathrm{s} ; 2$ ) relative difference of significant height $\left(H_{s}\right)$ smaller than $\left.20 \% ; 3\right)$ difference in peak frequency $\left(F_{p}\right)$ smaller than 20\%; and 4) difference in BLR between radar data and simulation using WW3 wave spectrum smaller than $4 \mathrm{~dB}$. Criterion 1 eliminates weak sea states for which secondorder Doppler spectrum is in general badly detected. Criteria 2 and 3 check the correctness of the large waves components in the omnidirectional spectrum. Criterion 4 ensures the proper directionality of the model spectrum at the Bragg waves. This criterion leads to a wind direction lying in the $0-45^{\circ}$ sector
TABLE I

Description of the 15 Selected Dates. $W S$ and $\phi_{W} S$ Are the Forcing Wind PARAMETERS OF WW3. $H_{s}$ AND $F_{p}$ ARE From THE BuOY, AND $m=k_{0} H_{S} / 4$ IS THE ROUGHNESS PARAMETER. THE BLR WAS ESTIMATED FROM RADAR DATA AND Simulation USing WW3. Values in PARENTHESIS ARE FROM WW3

\begin{tabular}{ccccccc}
\hline $\begin{array}{c}\text { Date } \\
(\mathrm{dd}: \mathrm{hh})\end{array}$ & $\begin{array}{c}W \\
(\mathrm{~m} / \mathrm{s})\end{array}$ & $\begin{array}{c}\phi_{w} \\
\left({ }^{\circ}\right.\end{array}$ & $\begin{array}{c}H_{S} \\
(\mathrm{~m})\end{array}$ & $\begin{array}{c}F_{p} \\
(\mathrm{~Hz})\end{array}$ & $\begin{array}{c}\text { BLR } \\
(\mathrm{dB})\end{array}$ & $m$ \\
\hline $12: 12$ & 11.1 & -57 & $1.3(1.2)$ & $0.20(0.23)$ & $-12.4(-13.6)$ & 0.11 \\
$14: 18$ & 9.2 & -45 & $1.9(1.8)$ & $0.12(0.12)$ & $-3.1(-6.6)$ & 0.16 \\
$16: 06$ & 12.4 & -103 & $2.3(2.3)$ & $0.13(0.14)$ & $11.7(11.8)$ & 0.19 \\
$16: 09$ & 12.9 & -102 & $3.0(3.1)$ & $0.11(0.12)$ & $10.7(13.1)$ & 0.25 \\
$16: 12$ & 12.1 & -105 & $3.9(3.5)$ & $0.11(0.11)$ & $11.8(12.8)$ & 0.33 \\
$16: 15$ & 13.9 & -92 & $4.0(3.9)$ & $0.11(0.11)$ & $9.4(10.2)$ & 0.34 \\
$16: 18$ & 16.3 & -46 & $4.3(4.3)$ & $0.10(0.10)$ & $-2.9(-4.5)$ & 0.36 \\
$16: 21$ & 16.7 & -52 & $4.4(4.2)$ & $0.10(0.10)$ & $-12.4(-13.4)$ & 0.37 \\
$17: 03$ & 15.5 & -43 & $3.3(4.0)$ & $0.11(0.11)$ & $-13.3(-16.1)$ & 0.28 \\
$17: 09$ & 10.7 & -40 & $2.6(2.8)$ & $0.11(0.11)$ & $-11.6(-15.1)$ & 0.22 \\
$17: 12$ & 11.9 & -43 & $2.4(2.7)$ & $0.11(0.12)$ & $-14.8(-17.4)$ & 0.20 \\
$17: 15$ & 14.1 & -46 & $2.4(2.7)$ & $0.11(0.12)$ & $-15.9(-19.2)$ & 0.21 \\
$20: 12$ & 11.5 & -54 & $1.9(1.9)$ & $0.15(0.14)$ & $-9.4(-13.3)$ & 0.16 \\
$20: 15$ & 11.8 & -42 & $2.1(2.2)$ & $0.15(0.13)$ & $-13.0(-14.5)$ & 0.18 \\
$24: 00$ & 8.8 & -59 & $1.0(0.9)$ & $0.21(0.25)$ & $-9.8(-8.8)$ & 0.09 \\
\hline
\end{tabular}

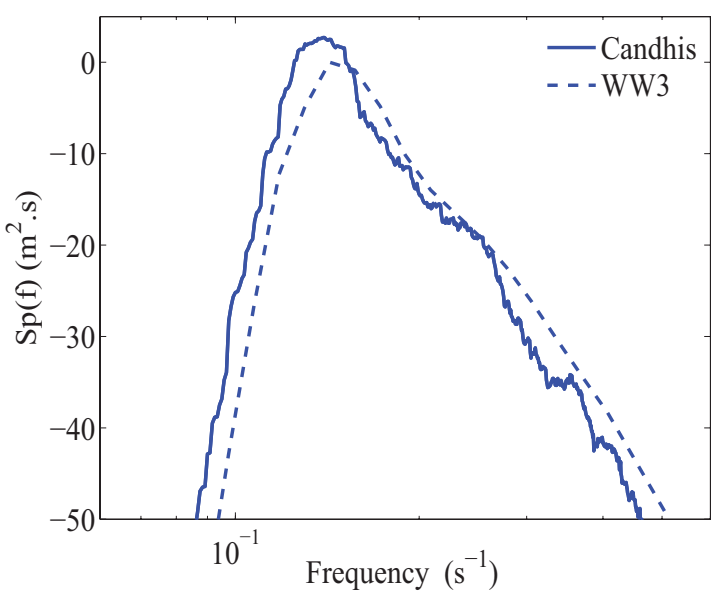

Fig. 8. Comparison between omnidirectional spectrum from WW3 model (solid line) and CANDHIS buoy (dashed line) on 16:06 (Table I).

(see Section VII). After selection according to these criteria, we obtained 15 cases as detailed in Table I.

For the 15 selected cases, the omnidirectional WW3 and in situ spectra are in good agreement for short waves (i.e., smaller than the peak wave). An example is shown on Fig. 8 on date 16:06. The WW3 directional wave spectra are typical of a wind wave system propagating in the direction of the wind (Fig. 9). An analysis (not detailed here) of the relationship between $H_{s}, F_{p}$, and wind speed shows that the fetches are relatively large $(\geq 60 \mathrm{~km})$.

Figs. 10-13 show the Doppler spectra for four generic cases. Again, a comparison is given between theoretical spectra (thin solid lines), simulated spectra in experimental conditions (dashed lines), and experimental measurement 


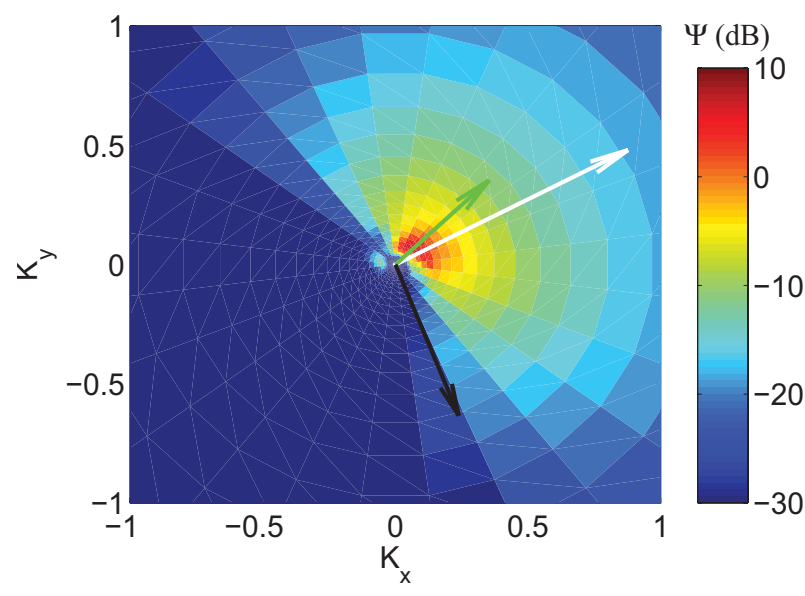

Fig. 9. Directional WW3 spectrum (in dB) for date 16:06 (Table I). Black arrow indicates the Bragg vector at $R_{C}=27 \mathrm{Km}$ and $\phi_{c}=120^{\circ}$. Green arrow indicates the peak wave direction. Write arrows indicates the WW3 forcing wind direction $\left(\phi_{w}=99^{\circ}\right)$.

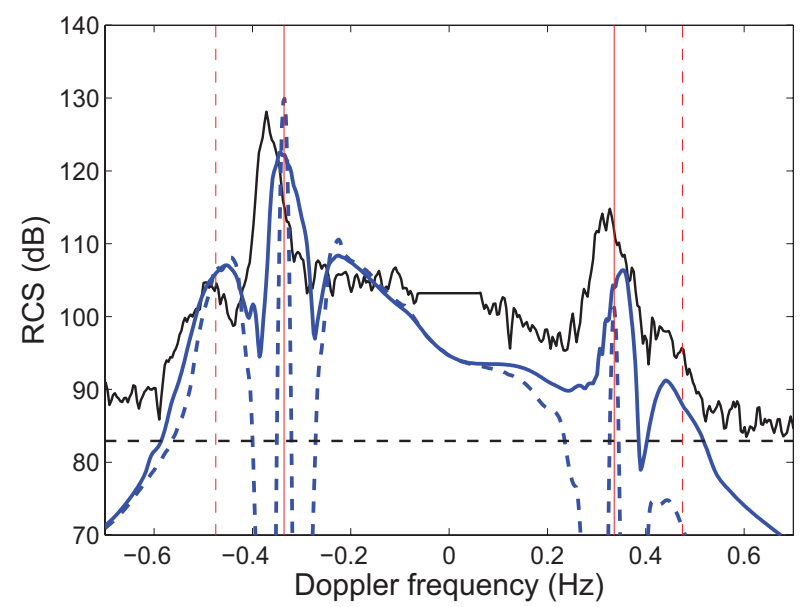

Fig. 10. Comparison of simulated and measured Doppler spectra on date $16: 21$.

(thick solid lines). As before, directional height spectrum used in the simulation is based in WW3. The horizontal dashed line indicates the background noise floor estimated with the method of [47].

The largest differences between modeled and experimental Doppler spectra are observed at the dates 12:12, 16:21, 17:03 (Fig. 10), 17:09, 17:12, 17:15, 20:12, 20:15, and 24:00. They correspond to the highest negative BLR values and will be referred to as the down cross wave (DCW) cases. For these cases, the BLR values are strongly affected by the cell weighting function. Since the latter is not always well characterized (attenuation factor, island shadowing effects, etc.,) this suggests that the criterion 4 based on BLR can fail for the DCW cases. A closer investigation of these cases shows that the characteristics of the radar system as modeled by the cell weighting function $\mathcal{G}$ have an important impact on the Doppler spectrum whenever the directional wave spectrum is weak in the upwind direction as is the case here with WW3 model. As a result, only the negative Doppler frequency part

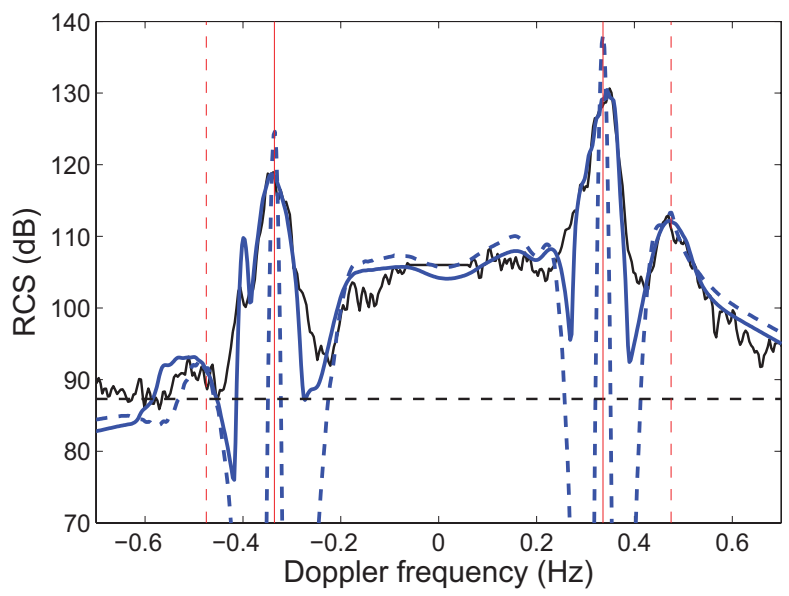

Fig. 11. Comparison of simulated and measured Doppler spectra on date 16:06.

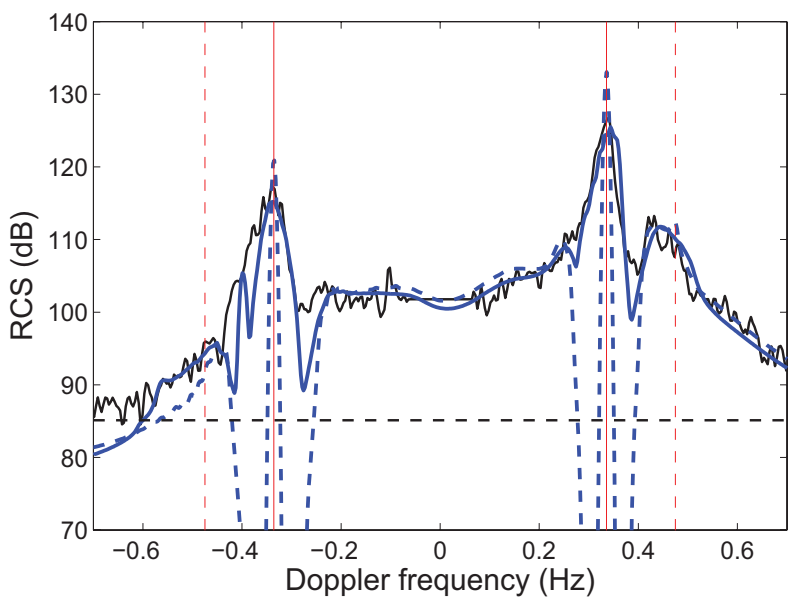

Fig. 12. Comparison of simulated and measured Doppler spectra on date $16: 15$.

of the spectrum should be relevant for wave inversion purpose. Such an issue is not encountered in the other configurations.

Save for these differences, a good agreement has been generally found between experimental and simulated Doppler spectra. The radar system characteristics have little influence on the second-order spectrum except at the secondary peaks (swell and hydrodynamic peaks), which are smoothed. A broadening of the first-order peaks is observed (e.g., Fig. 11) and has already been explained by the effects of antenna gain in Section V. The appearance of a physically nonexpected secondary peak in the vicinity of the Bragg peak (e.g., at $f_{d}=-0.4 \mathrm{~Hz}$ in Figs. 11 and 12) has also been explained in this section. Note that this undesirable peak is awkward when it comes to the estimation of the swell peaks because they occur in the same range of Doppler frequency.

According to the results of the bistatic RCS model presented in Section II, the spectral peak of the omnidirectional wave spectrum appears as four local maxima on both sides of each Bragg line with a relative position almost equal to $F_{p}$. This phenomenon is well known in the monostatic configuration. It was theoretically predicted in [48] and has been often reported in experiments [49]-[51]. These spectral maxima are generally 


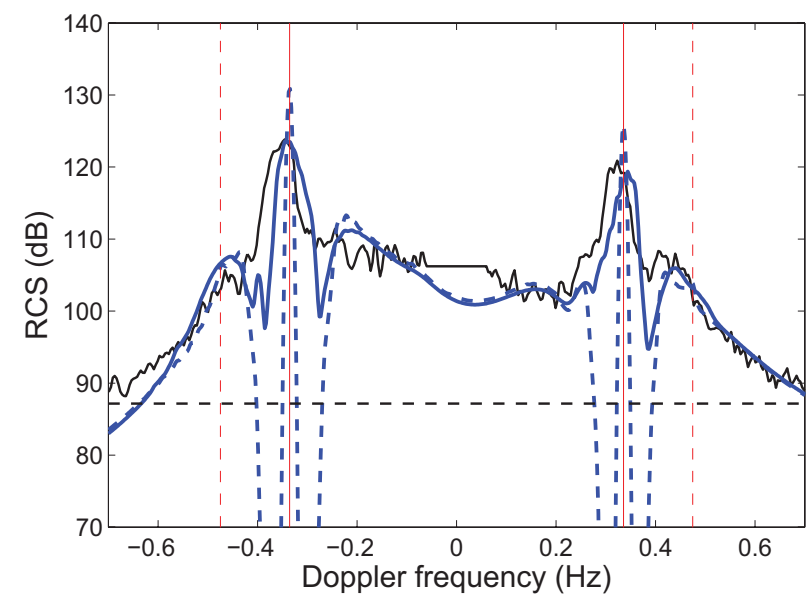

Fig. 13. Comparison of simulated and measured Doppler spectra on date 16:18.

well identified in our Doppler spectra (e.g., Fig. 11) and behave as expected, i.e., they move closer to the Bragg lines as $F_{p}$ decreases. This is observed in Figs. 11-13 corresponding to $F_{p}=0.13,0.11$, and $0.10 \mathrm{~Hz}$, respectively. At low $F_{p}$, i.e., for high sea states (Fig. 12), the maxima, due to the dominant waves tend to merge into the first-order peaks. In these cases, the second-order Doppler spectrum can be difficult to use for wave inversion purposes. It should be noted that the overall asymmetry of Doppler spectra in Figs. 11-13 reflects the change of wind from up-cross to down-cross direction (I). We also note the influence of surface currents that shifts both first- and second-order Doppler spectra (e.g., Fig. 10).

In the regions $\left|f_{d}\right|>f_{B}$, the maxima, due to the dominant waves, can be difficult to discriminate from the hydrodynamic peaks at $\pm \sqrt{2} f_{B}$ because of the smoothing effect of the system gains (e.g., Fig. 11 in the vicinity of $\sqrt{2} f_{B}$ ).

An important parameter governing the validity of the second-order bistatic RCS is the roughness parameter $m=k_{0} H_{s} / 4$. In principle, it must be less than 1 for the applicability of the perturbation method on which (1) relies. Evidence of departures from the theory were found for $m=0.4$ [52]. Our $m$ values are less than this limiting value, and we actually observed good agreements between experimental and simulated Doppler spectra, whereas they can differ in severe storm condition [53] or in shallow waters [54].

\section{Effect of Islands}

We have assessed the relevance and limitations of a bistatic simulator in a specific experimental configuration in the coastal area of Toulon. One important point is the presence of islands in the short-range field of view of the radar, namely, Porquerolles island and the Giens Peninsula (see the map in Fig. 3). We could not precisely evaluate the attenuation due to these islands and simply ignored the masked directions. However, the presence of these islands is probably a favorable factor for the interpretation of Doppler spectra, as it can block undesirable side lobes of the emitting antenna pattern when the main lobe is aimed at some other unmasked direction (this is the case for the chosen grid point of the WW3 model, see Fig. 3). Hence, islands can be used as natural side lobe rejectors and therefore improve the performance of the bistatic system in neighboring areas.

\section{CONCLUSION}

In this paper we developed a bistatic HF Doppler spectrum simulator based on the second-order theory in [16] and including the characteristics of the radar, such as antenna gains and propagation effects. We have run this simulator in the configuration of a WERA system recently used over the Mediterranean coast. Using the spectral model WW3 validated by in situ buoy measurements, we were able to compare the simulated and experimental Doppler spectra.

We found that the effects of the radar system are significant for the first-order peaks. In bistatic configuration, experimental artifacts, such as antenna side lobes, can smear the firstorder echo over a frequency interval corresponding to the Bragg frequency variation in azimuth and range. The firstorder Bragg peaks are broadened, not only by the finite integration time, but also by undesirable echoes originating from nontargeted cells. Moreover, the actual gains can modify the BLR ratio in such a way that BLR values no longer reflect the Bragg wave properties. This holds particularly true when the wave spectrum presents little energy in the up-/down-wind sector. In addition, for high sea states, the broadening of Bragg peaks can mask the second-order signature long waves.

The second-order Doppler spectrum is less affected by system gains except possibly at second-order peaks. The swell peaks can be masked by the wind-driven Doppler spectrum. The hydrological peaks are smoothed. We analyzed the simulations for which the modeled directional wave spectra were most realistic. These simulations accurately reproduced the experimental data, indicating that the bistatic theory is relevant and could be used for the purpose of wave spectrum inversion.

\section{APPENDIX A}

\section{BistATIC KERNELS}

The expression of the kernel in (3) is

$$
\mathbb{B}\left(\boldsymbol{K}, \epsilon_{1}, \epsilon_{2}\right)=\Gamma_{e}(\boldsymbol{K})+\Gamma_{h}\left(\boldsymbol{K}, \epsilon_{1}, \epsilon_{2}\right) .
$$

$\Gamma_{e}$ and $\Gamma_{h}$ are the hydrodynamic and electromagnetic coupling coefficients, respectively. The electromagnetic coupling coefficients used here are

$$
\Gamma_{e}=\frac{\left(\boldsymbol{K} \cdot \boldsymbol{u}_{i}\right)\left(\boldsymbol{K}_{2} \cdot\left(\boldsymbol{K}-k_{0} \boldsymbol{u}_{i}\right)\right)}{2 k_{0} \cos ^{2}\left(\phi_{b i}\right)\left(\sqrt{\boldsymbol{K} \cdot\left(\boldsymbol{K}-2 k_{0} \boldsymbol{u}_{i}\right)}+i k_{0} \Delta\right)}
$$

with $\boldsymbol{u}_{i}$ the unit vector from the transmitter to the radar cell (see Fig. 1). $\Delta$ is the normalized surface impedance given by [24]

$$
\Delta=\frac{1}{N} \sqrt{1-\frac{1}{N^{2}}}
$$

where $N$ is the refractive index of the surface

$$
N=\sqrt{\epsilon_{r}+i \frac{\sigma_{s}}{\epsilon_{0} \omega_{0}}}
$$

$\epsilon_{r}$ is the relative permittivity and $\sigma_{s}$ the conductivity of sea, and $\omega_{0}$ is the radar pulsation. The expression (A2) differs from its counterpart appearing in [16] by the presence of 
a term involving $i k_{0} \Delta$. This "correction" appears for the monostatic coefficient in [3], [17], and [55] and is justified by the finite conductivity of the sea. In the bistatic case, we have introduced this term in a heuristic way to avoid nonintegrable singularities. A rigorous derivation of this result, which remains to be established, would take us too far from the main objectives of this paper.

The deep water expression of the hydrodynamic coupling coefficients is used in this paper (see [17] and [56]). A general expression can be found in [57].

\section{APPENDIX B}

\section{Calculation of the Cell Surface Element}

In a frame of reference centered at the receiver with polar coordinates $R_{r x}$ and $\phi$ ( $\phi$ the receiver azimuthal angle and $R_{r x}$ the distance from the receiver to the cell, see Fig. 9), the differential $\mathrm{d} A$ is given by

$$
\mathrm{d} A=R_{r x}(R, \phi) \mathrm{d} R_{r x} \mathrm{~d} \phi .
$$

In these coordinates, $R_{r x}$ is given by

$$
R_{r x}(R, \phi)=\frac{R\left(1-e^{2}\right)}{1+e \cos (\phi)}
$$

where $e=f / R$ is the ellipse eccentricity and $f$ is the halfdistance between the two focus (see Fig. 1). It follows that $\mathrm{d} A$ can be written as

$$
\mathrm{d} A=R_{r x}(R, \phi)\left|\frac{\delta R_{r x}}{\delta R}\right| \mathrm{d} R \mathrm{~d} \phi
$$

with

$$
\frac{\delta R_{r x}}{\delta R}=\frac{R^{2}+2 R f \cos (\phi)+f^{2}}{(a+f \cos (\phi))^{2}} .
$$

\section{APPENDiX C}

\section{Model of Directional Sea Height Spectrum}

The directional spectrum is given by the product of the unidirectional spectrum and the spreading function

$$
\mathrm{S}(\boldsymbol{K})=\mathrm{S}_{u}(K) \mathrm{D}(\phi) .
$$

In this paper, we used as $\mathrm{S}_{u}(K)$ the semiempirical model given in [21] for a saturated sea (infinite fetch). It depends on $U_{19.5}$, which is the wind speed at $19.5 \mathrm{~m}$ above sea.

A commonly used model of spreading function $\mathrm{D}(\phi)$ was proposed by [58], which is

$$
\mathrm{D}(\phi)=\frac{\epsilon+(1-\epsilon) \cos ^{s}\left(\frac{\phi}{2}\right)}{N(s, \epsilon)}
$$

where $\phi$ is the angular direction relative to the wind direction, and $N(s, \epsilon)$ is a normalization factor such that $\int_{0}^{2 \pi} \mathrm{D}(\phi)$ $\mathrm{d} \phi=1$. The parameter $s$ characterizes the width of the angular distribution, while $\epsilon$ was first introduced by [59] to fit HF radar measurements. Physically, $\epsilon$ represents the fraction of energy that propagates against the wind direction.

Models for $s$ can be found in the literature [60], [61] under the assumption of unimodal wave propagation. However, unimodality is not always valid and many studies support bimodality, especially at the early stage of wave development (e.g., [62], [63]). In order not to deviate too far from the main objective of the paper, we chose to use the simple cardioid model with constant $s$ and $\epsilon$ values. These parameters were fitted with the experimental data in the mean-square sense using the BLRs and found to be $s=8.5$ and $\epsilon=$ $0.027(-15.7 \mathrm{~dB})$, respectively. The value of $s$ is consistent with the classical models described above, e.g., $s=8.5$ corresponds to a Bragg to peak frequency ratio $f_{B} / f_{p}=1.7$ in Mitsuyasu's model for a fully developed sea and also to the estimations given in [42]. Recently, the $\operatorname{sech}^{2}$ functional form was proposed to replace the cardioid model to fit HF/VHF radar measurement [42], [45]. We did not, however, use this model, which we found less performing in our context.

\section{REFERENCES}

[1] D. E. Barrick, "First order theory and analysis of MF/HF/VHF scatter from the sea," IEEE Trans. Antennas Propag., vol. 20, no. 1, pp. 2-10, Jan. 1972.

[2] D. E. Barrick, "Remote sensing of sea state by radar," in Proc. IEEE Int. Conf. Eng. Ocean Environ. Ocean 72, Sep. 1972, pp. 186-192.

[3] B. J. Lipa and D. E. Barrick, "Extraction of sea state from HF radar sea echo- mathematical theory and modeling," Radio Sci., vol. 21, no. 1 pp. 81-100, 1986.

[4] Y. Hisaki, "Nonlinear inversion of the integral equation to estimate ocean wave spectra from HF radar," Radio Sci., vol. 31, no. 1, pp. 25-39, 1996.

[5] E. W. Gill, M. L. Khandekar, R. K. Howell, and J. Walsh, "Ocean surface wave measurement using a steerable high-frequency narrowbeam ground wave radar," J. Atmosph. Ocean. Technol., vol. 13, no. 3, pp. 703-713, 1996.

[6] L. R. Wyatt, "Limits to the inversion of HF radar backscatter for ocean wave measurement," J. Atmosph. Ocean. Technol., vol. 17, no. 12, pp. 1651-1665, 2000.

[7] R. J. Ramos, H. C. Graber, and B. K. Haus, "Observation of wave energy evolution in coastal areas using HF radar," J. Atmosph. Ocean. Technol., vol. 26, no. 9, pp. 1891-1909, 2009.

[8] K-W. Gurgel and T. Schlick, "HF radar wave measurements in the presence of ship echoes-problems and solutions," Eur. Ocean., vol. 2. Jun. 2005, pp. 937-941.

[9] L. Sevgi, A. M. Ponsford, and H. C. Chan, "An integrated maritime surveillance system based on high-frequency surface-wave radars, part 1: Theoretical background and numerical simulations," IEEE Antennas Propag. Mag., vol. 43, no. 4, pp. 28-43, Aug. 2001.

[10] B. Lipa, B. Nyden, D. S. Ullman, and E. Terrill, "Seasonde radial velocities: Derivation and internal consistency," IEEE J. Ocean. Eng., vol. 31 , no. 4 , pp. 850-861, Oct. 2006.

[11] C. C. Teague, "Bistatic-radar techniques for observing long-wavelength directional ocean-wave spectra," IEEE Trans. Geosci. Electron., vol. 9 , no. 4, pp. 211-215, Oct. 1971.

[12] B. Lipa, C. Whelan, B. Rector, and B. Nyden, "HF radar bistatic measurement of surface current velocities: Drifter comparisons and radar consistency checks," Remote Sens., vol. 1, no. 4, pp. 1190-1211, 2009.

[13] H. J. Roarty, E. Rivera Lemus, E. Handel, S. M. Glenn, D. E. Barrick, and J. Isaacson, "Performance evaluation of seasonde high-frequency radar for vessel detection," Marine Technol. Soc. J., vol. 45, no. 3 , pp. 14-24, 2011.

[14] W. Huang, E. W. Gill, W. Wu, and L. Li, "Measurement of sea surface wind direction using bistatic high-frequency radar," IEEE Trans. Geosci. Remote Sens., vol. 50, no. 10, pp. 4117-4122, Oct. 2012.

[15] E. W. Gill and J. Walsh, "High-frequency bistatic cross sections of the ocean surface," Radio Sci., vol. 36, no. 6, pp. 1459-1475, 2001.

[16] E. W. Gill, W. Huang, and J. Walsh, "On the development of a secondorder bistatic radar cross section of the ocean surface: A high-frequency result for a finite scatering patch," IEEE J. Ocean. Eng., vol. 31, no. 4 , pp. 740-750, Oct. 2006.

[17] J. Walsh, J. Zhang, and E. W. Gill, "High-frequency radar cross section of the ocean surface for an FMCW waveform," IEEE J. Ocean. Eng., vol. 36, no. 4, pp. 615-626, Oct. 2011. 
[18] E. W. Gill, "The scattering of high-frequency electromagnetic radiation from the ocean surface: An analysis based on a bistatic ground-wave radar configuration," Ph.D dissertation, Dept. Electr. \& Electron. Eng., Univ. Newfoundland, NF, Canada, 1999.

[19] J. Walsh and E. W. Gill, "An analysis of the scattering of high-frequency electromagnetic radiation from rough surfaces with application to pulse radar operating in backscatter mode," Radio Sci., vol. 35, no. 6, pp. 1337-1359, 2000.

[20] E. W. Gill and J. Walsh, "Bistatic form of the electric field equations for the scattering of vertically polarized high-frequency ground wave radiation from slightly rough, good conducting surfaces," Radio Sci., vol. 35 , no. 6, pp. 1323-1336, 2000.

[21] W. Pierson and L. Moskowitz, "A proposed spectal form for fully developed seas based upon the similarity theory of S. A. kitaigorodskii," J. Geophys. Res., vol. 69, no. 24, pp. 5181-5190, 1964.

[22] K.-W. Gurgel, G. Antonischki, H.-H. Essen, and T. Schlick, "The university of hamburg WERA HF radar-theory and solutions," in Proc. 1st Int. Radiow. Oceanogr. Workshop, 2001, pp. 1-7.

[23] D. E. Barrick, "Theory of HF and VHF propagation across the rough sea 1 , the effective surface impedance for a slightly rough highly conducting medium at grazing incidence," Radio Sci., vol. 6, no. 5, pp. 517-526, 1971.

[24] J. R. Wait, "The ancient and modern history of EM ground-wave propagation," IEEE Antennas Propag. Mag., vol. 40, no. 5, pp. 7-24, Oct. 1998

[25] K.-W. Gurgel, G. Antonischki, H.-H. Essen, and T. Schlick, "Wellen radar (WERA) a new ground-wave based HF radar for ocean remote sensing," Coastal Eng., vol. 37, nos. 3-4. pp. 219-234, 1998.

[26] (2013). Mediterranean Institute of Oceanography [Online]. Available: http://mio. pytheas. univ-amu. fr

[27] T. N. Osterdock, D. C. Westcott, and Q. D. Hua, "Gps synchronized frequency/time source," U.S. Patent 5440313, Jan. 24, 1995.

[28] D. E. Barrick, P. M. Lilleboe, B. J. Lipa, and J. Isaacson, "Ocean surface current mapping with bistatic hf radar," U.S. Patent 6774837, May 15, 2001.

[29] D. E. Barrick, P. M. Lilleboe, and C. C. Teague, "Multi-station hf fmcw radar frequency sharing with gps time modulation multiplexing," U.S. Patent 6856276, May 15, 2001.

[30] (1972). CANDHIS [Online]. Available: http://candhis. cetmef. developpement-durable.gouv.fr

[31] (May 17, 2010). PREVIMER-Observations et Prévisions Côtières [Online]. Available: http://www. previmer. org

[32] H. L. Tolman, "A mosaic approach to wind wave modeling," Ocean Model., vol. 25, no. 1, pp. 35-47, 2008.

[33] H. L. Tolman, "User manual and system documentation of WAVEWATCH-III version 3.14," MMAB Contribution, Houston, TX, USA, Tech. Rep. 276, 2009.

[34] F. Ardhuin, L. Marié, N. Rascle, P. Forget, and A. Roland, "Observation and estimation of lagrangian, stokes, and eulerian currents induced by wind and waves at the sea surface," J. Phys. Oceanogr., vol. 39, no. 11, pp. 2820-2838, 2009 .

[35] L. Sevgi, "A mixed-path groundwave field-strength prediction virtual tool for digital radio broadcast systems in medium and short wave bands," IEEE Antennas Propag. Mag., vol. 48, no. 4, pp. 19-26, Aug. 2006.

[36] G. Apaydin and L. Sevgi, "A novel split-step parabolic-equation package for surface-wave propagation prediction along multiple mixed irregularterrain paths," IEEE Antennas Propag. Mag., vol. 52, no. 4, pp. 90-97, Nov. 2010.

[37] G. Apaydin and L. Sevgi, "Numerical investigations of and path loss predictions for surface wave propagation over sea paths including Hilly island transitions," IEEE Trans. Antennas Propag., vol. 58, no. 4, pp. 1302-1314, Apr. 2010.

[38] H. H. Essen, K. W. Gurgel, and T. Schlick, "On the accuracy of current measurements by means of HF radar," IEEE J. Ocean. Eng., vol. 25, no. 4, pp. 472-480, Oct. 2000.

[39] Y. Hisaki and M. Tokuda, "VHF and HF sea echo doppler spectrum for a finite illuminated area," Radio Sci., vol. 36, no. 3, pp. 425-440, 2001.

[40] J. Zhang, J. Walsh, and E. W. Gill, "Inherent limitations in highfrequency radar remote sensing based on bragg scattering from the ocean surface," IEEE J. Ocean. Eng., vol. 37, no. 3, pp. 395-406, Jul. 2012.
[41] W. Huang, S. Wu, E. W. Gill, B. Wen, and J. Hou, "HF radar wave and wind measurement over the eastern china sea," IEEE Trans. Geosci. Remote Sens., vol. 40, no. 9, pp. 1950-1955, Sep. 2002.

[42] L. R. Wyatt, "Short wave direction and spreading measured with HF radar," J. Atmosph. Ocean. Technol., vol. 29, no. 2, pp. 286--299, 2011.

[43] R. H. Stewart and J. R. Barnum, "Radio measurements of oceanic winds at long ranges: An evaluation," Radio Sci., vol. 10, no. 10, pp. 853-857, 1975.

[44] J. A. Harlan and T. M. Georges, "An empirical relation between oceansurface wind direction and the bragg line ratio of HF radar sea echo spectra," J. Geophys. Res., vol. 99, no. C4, pp. 7971-7978, 1994.

[45] W. Shen, K.-W. Gurgel, G. Voulgaris, T. Schlick, and D. Stammer, "Wind-speed inversion from HF radar first-order backscatter signal," Ocean Dynamics, vol. 62, no. 1, pp. 105-121, 2012.

[46] K.-W. Gurgel, H. H. Essen, and T. Schlick, "An empirical method to derive ocean waves from second-order bragg scattering: Prospects and limitations," IEEE J. Ocean. Eng., vol. 31, no. 4, pp. 804-811, Oct. 2006.

[47] P. H. Hildebrand and R. S. Sekhon, "Objective determination of the noise level in doppler spectra," J. Appl. Meteorol., vol. 13, no. 7, pp. 808-811, 1974.

[48] K. Hasselmann, "Determination of ocean wave spectra from doppler radio return from the sea surface," Nature, vol. 229 , no. 1 , pp. 16-17, 1971.

[49] B. J. Lipa, D. E. Barrick, and J. W. Maresca, "HF radar measurements of long ocean waves," J. Geophys. Res., vol. 86, no. C5, pp. 4089-4102, 1981.

[50] P. Forget, P. Broche, J. C. De Maistre, and A. Fontanel, "Sea state frequency features observed by ground wave HF doppler radar," Radio Sci., vol. 16, no. 5, pp. 917-925, 1981.

[51] P. Broche, P. Forget, J. C. de Maistre, J. L. Devenon, and M. Crochet, "VHF radar for ocean surface current and sea state remote sensing," Radio Sci., vol. 22, no. 1, pp. 69-75, 1987.

[52] L. R. Wyatt, "High order nonlinearities in HF radar backscatter from the ocean surface," IEE Proc. Radar, Sonar Navigat., vol. 142, no. 6, pp. 293-300, Dec. 1995.

[53] S. P. Kingsley, A. Matoses, and L. R. Wyatt, "Analysis of second order HF radar sea spectra recorded in storm conditions. in Proc. OCEANS'98 Conf., vol. 1. Oct. 1998, pp. 459-462.

[54] P. Broche and P. Forget, "Shallow water waves observed by a VHF groundwave Doppler radar," Int. J. Remote Sens., vol. 14, pp. 2301-2314, Aug. 1993.

[55] R. E. Robson, "Simplified theory of first-and second-order scattering of HF radio waves from the sea," Radio Sci., vol. 19, no. 6, pp. 1499-1504, 1984.

[56] B. L. Weber and D. E. Barrick, "On the nonlinear theory for gravity waves on the ocean's surface. Part I: Derivations," J. Phys. Oceanogr., vol. 7, no. 1, pp. 3-10, 1977.

[57] J. Walsh, R. Howell, and B. Dawe, "Model development for evaluation studies of ground wave radar," in Proc. Contract Rep. Conf., 1990, pp. 90-C14.

[58] M. S. Longuet-Higgins, D. E. Cartwright, and N. D. Smith, "Observation of the directional spectrum of sea waves using motions of a floating buoy," in Proc. Ocean Wave Spectra Conf., 1963, pp. 111-136.

[59] G. L. Tyler, C. C. Teague, R. H. Stewart, A. M. Peterson, W. H. Munk, and J. W. Joy, "Wave directional spectra from synthetic aperture observations of radio scatter," Deep Sea Res. Oceanogr. Abstracts, vol. 21, no. 12, pp. 989-1016, 1974.

[60] H. Mitsuyasu, F. Tasai, T. Suhara, S. Mizuno, M. Onkusu, T. Honda, and T. Rukiiski, "Observations of the directional spectrum of ocean waves using a cloverleaf buoy," J. Phys. Oceanogr., vol. 5, no. 4, pp. 751-761, 1975.

[61] D. E. Hasselmann, M. Dunckel, and J. A. Ewing, "Directional wave spectra observed during JONSWAP 1973," J. Phys. Oceanogr., vol. 10, no. 8, pp. 1264-1280, 1980.

[62] Y. Yuan and N. E. Huang, "A reappraisal of ocean wave studies," $J$. Geophys. Res., vol. 117, no. C11, p. C00J27, Nov. 2012.

[63] E. Gagnaire, M. Benoit, and P. Forget, "Analysis of the structure of ocean wave directional spectrum inferred from quasi-exact computations of non-linear wave-wave interactions," J. Geophys. Res., vol. 115, pp. 1-37, Apr. 2009. 


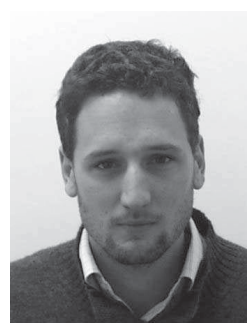

Samuel Grosdidier received the Masters degree in environmental oceanography and remote sensing from the Université du Sud Toulon Var', Toulon, France, in 2007, and the Ph.D. degree in electrical engineering and signal processing from the the Université de Brest, Brest, France, in 2010.

$\mathrm{He}$ has a Post-Doctaral position at the Mediterranean Institute of Oceanography (MIO), Toulon, France, since 2011. His current research interests include remote sensing of ocean surface wave by high-frequency radar.

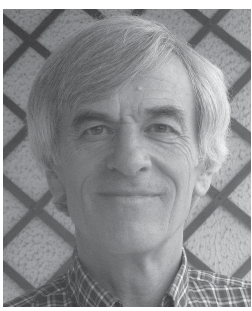

Philippe Forget received the B.Eng. degree from the École Nationale Supérieure des Techniques Avancées', Paris, France, in 1974, the 'Thèse de 3e Cycle' in oceanography from Paris VI University, Paris, in 1979, and the 'Thèse de Doctorat d'Etat' in oceanography from Sud Toulon-Var University, La Garde, France, in 1983.

$\mathrm{He}$ is currently a Director of Research at CNRS, Mediterranean Institute of Oceanography (CNRS/IRD/Aix-Marseille and Sud Toulon-Var Universities), Nicosia, France. He has worked in various fields of coastal oceanography (surface waves, coastal dynamics, internal waves, ocean-atmosphere interactions), electromagnetism (scattering by the sea surface, radio wave propagation), ocean optics, and remote sensing (HF/VHF radars, SAR and other microwave techniques, optical sensors). He has been involved in several mission projects of Centre National d'Etudes Spatiales (CNES), Toulouse, France, and has conducted several oceanographic and remote sensing (airborne) field campaigns.

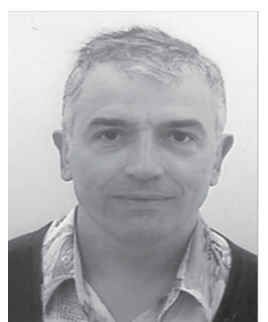

Yves Barbin received the Degree and Masters degrees from University Paris 6, Paris, France, and the Ph.D. degree in signal processing applied to geophysics from Institut National Polytechnique de Grenoble, Grenoble, France.

He had been involved in radar applications for space science. He designed the Mars96 radar for the in-situ deep EM sounding of planet Mars, and the Concert instrument for the cometary ESA-mission Rosetta. He has been with MIO (formerly LSEET) since 2001, where he has been developing radio oceanagraphy activity. His background, technical reports, and papers concern electromagnetism, signal processing, space sciences, electronics, applied mathematics, embedded computers, real-time systems, instrument designs, and cognitive science.

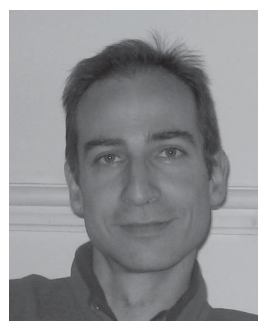

Charles-Antoine Guérin received the B.Eng. degree from the Ecole Nationale Supérieure de l'Aéronautique et de l'Espace, Toulouse, France, in 1994, and the Ph.D. degree in theoretical physics from the University of Aix-Marseille, France, in 1998

He is currently a Professor and Researcher with the Mediterranean Institute of Oceanography, University of Toulon, Toulon. He specializes in electromagnetic wave theory and its application to ocean remote sensing. 